\title{
Effects of Materials Based on Acrylic Resines on Inflammatory Markers IL-8 and TGF $\beta 1$ in Gingival Crevicular Fluid
}

\begin{abstract}
CRISTIAN SEBASTIAN VLAD ${ }^{1}$, VICTOR DUMITRASCU1*, DALIBORCA CRISTINA VLAD ${ }^{1,2}$, ROXANA POPESCU ${ }^{2,3}$, ADINELA CIMPORESCU ${ }^{2}$, CORINA FL ANGEA ${ }^{1,2}$, ADELINA CHEVERESAN ${ }^{1}$, SIMONA SIPOS ${ }^{1}$, BEATRICE BARAC ${ }^{1}$, IOANA MALITA ${ }^{1}$ ${ }^{1}$ University of Medicine and Pharmacy Victor Babes, Pharmacology Department, 2 Eftimie Murgu Sq., 300041, Timisoara, Romania

${ }^{2}$ Clinical County Emergency Hospital Pius Branzeu, 156 Liviu Rebreanu Blvd., 300723, Timisoara, Romania

3University of Medicine and Pharmacy Victor Babes, Department of Cell and Molecular Biology, 2 Eftimie Murgu Sq., 300041, Timisoara, Romania

Materials based on acrylic resins are commonly used in dental practice. These are obtained through various technologies, which determine the chemical, physical and biological properties of the final product, which can influence the inflammatory processes in the periodontal tissue. To evaluate the effects of these materials, we identified the concentrations of TGF $\beta 1$ and IL 8 in crevicular fluid in 23 patients with temporary dentures made of polymethyl methacrylate by two polymerization methods: (1) a product processed immediately prior to application, wherein the polymerization of the material occurs in the oral cavity; and (2) a product processed in the dental laboratory from a prepolymerized block (block-type PMMA), and applied directly into the patient's mouth. The results of our study revealed a significant correlation between the IL-8 inflammation marker and the clinical parameters in the periodontal tissue exposed to the polymerization of the material in the oral cavity.
\end{abstract}

Keywords: GCF, IL-8, TGF $\beta 1$, poly-methyl methacrylate (PMMA)

It is well known that acrylic resin products are commonly used in a variety of medical procedures due to their biological activities, repairment properties, low costs, ease of handling, and also due to the fact that they offer an aesthetic quality of the temporary crowns.

In dentistry, poly-methyl methacrylate (PMMA) has clinical applications in the therapeutic strategies of temporary restoration of dental crowns for variable periods of time [1]. PMMA polymerization is produced by two methods: auto-polymerization (cold-cured) and heatpolymerization (heat-cured). The polymerization process of PMMA plays a key role in practical application of the product in order to achieve its biological reparative properties. Following polymerization process, toxic residual monomeric products are released. If the dental material polymerization process is performed in oral cavity, the residual products released into the oral aqueous medium will alter the bio-compatibility mechanisms, generating cytotoxicity [2].

Periodontal tissue is constituted of epithelial and conjunctive cell populations capable of generating defense mechanisms against pathogens or foreign bodies in the oral cavity. The cellular response consists in the synthesis of local and systemic pro-inflammatory molecules, such as cytokines and chemokines [3]. Data on the biological potential of restorative products used in dental medicine are controversial. Some studies in the literature mention antibacterial properties of PMMA [4], while other studies suggest that these therapeutic products may favor the formation of bacterial plaques [5], which will lead to the installation and involvement of the inflammatory processes. Evidence of these molecular markers of the inflammatory process is useful in both, diagnosis and management of periodontal pathology.

The aim of the study was to evaluate and correlate biologically and clinically, the inflammatory response of the periodontal tissue exposed to the polymerization of resin-based acrylic material. In this purpose we tested two products commonly used in dental practice: product 1 which was processed in the dental office prior to application step, in which case the polymerization reaction occurred after application into the patient's mouth; and product 2 which was applied directly into the patient's mouth without processing, in which case the polymerization reaction was stopped before the application step. The study proposed to highlight the levels of IL-8 and TGF $\beta 1$ in patients who have received dental treatment by applying the two products, and to correlate these markers with clinical parameters.

\section{Experimental part}

Materials and methods

23 patients aged between 40-49 years were recruited at the Dentissimo Dental Care Clinic for treatment, and dental restoration by temporary prosthetic crowns. Subjects were grouped in two lots: (A) patients treated with product 1 (12 patients) and (B) patients treated with product 2 (11 patients). Patients included in our study were exposed to PMMA for a period of 3 months. The inclusion criteria in the study were: nonsmokers, clinically healthy, with no history of chronic pathology, alcohol-free, or any other treatment given over the past 2 months. All patients enrolled in the study signed an informed consent. The clinical parameters analyzed were: plaque index, gingival index, and pocket depth [6].

To assess the molecular markers of inflammation we determined the levels of IL-8 and TGF $\beta 1$ from gingival crevicular fluid (GCF). Gingival fluid collection was performed using absorbent paper according to literature protocols. [7] 5 samples were taken for each patient on disease site (DS) (fig. 1). In parallel, GCF was collected from the non-disease sites (NDS) from the same patients. 


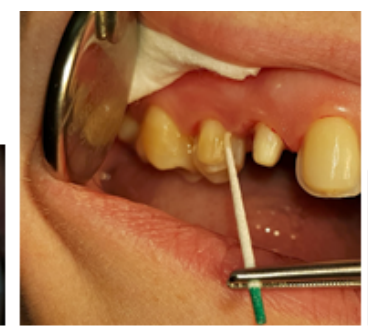

Contamination with saliva and blood was avoided, or these samples were removed from the study. Patients did not consume food or water and did not wash their teeth at least two hours before collection time. The paper strips were placed in sterile tubes containing $300 \mu \mathrm{L}$ of PBS (phosphorous buffered saline), and centrifuged at 1000g, $15 \mathrm{~min}$ at $4^{\circ} \mathrm{C}$. Samples were stored at $-80^{\circ} \mathrm{C}$ until cytokine assays were performed. Determination levels of interest molecules in GCF was performed by the ELISA method using the IL-8 (Human IL-8 PicoKine ${ }^{\text {TM }}$ ELISA Kit manufacturers (Boster Biological Technology, Pleasanton CA, USA, Catalog \# EK0413) and TGF 31 Human TGF Beta 1 PicoKine ELISA Kit (Boster Biological Technology, Pleasanton CA, USA, Catalog \# EK0513), test range (15.6pg/ mL -1000pg/mL). Optical density was measured at $450 \mathrm{~nm}$. For statistical analysis we used IBM SPSS Statistics. Applied statistical method was linear regression.

\section{Results and discussions}

Experimental and control sites were scored for the folowing clinical parameters: plaque index, gingival index, and pocket depth. Determination of IL-8 and TGF $\beta 1$ levels from GCF was performed by reference to the calibration curve corresponding to the kit insert. For both cytokines, the calibration curve comprised a number of 8 standard concentrations (0-15.6-31.2-62.5-125-250-500-1000 pg / $\mathrm{mL}$ ) (fig. 2,3).

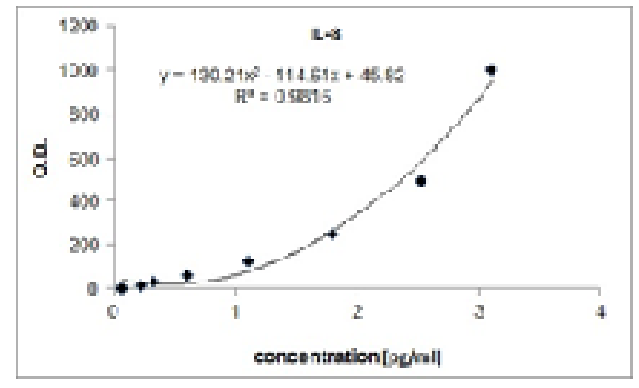

Fig. 2. IL-8

calibration

curve

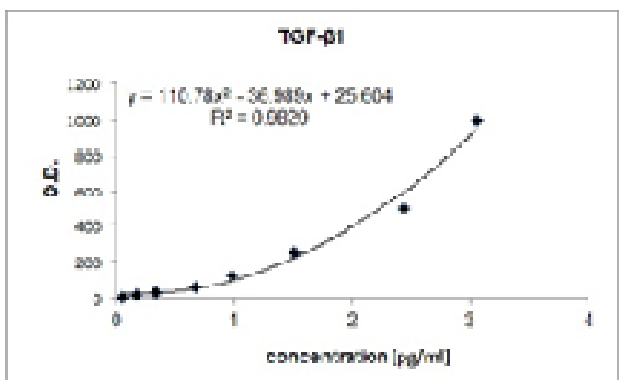

Fig. 3.TGF $\beta 1$ calibration curve

We followed the analysis of IL- 8 and TGF $\beta 1$ concentrations in GCF. From all the cases taken into the study, 23/23 showed positive levels of IL-8, whereas the TGFấ 1 was detectable only in $3 / 23$ of the studied cases. For all variables taken into account, there were statistically significant differences between product 1 and product 2 :

\begin{tabular}{|c|c|c|c|c|c|}
\hline & Products & $\mathbf{N}$ & Mean & $\begin{array}{c}\text { Std. } \\
\text { Deviation }\end{array}$ & $\begin{array}{c}\text { Std. Error } \\
\text { Mean }\end{array}$ \\
\hline \multirow{2}{*}{$\begin{array}{c}\text { IL-8 } \\
\text { DS (pg/ml) }\end{array}$} & Product 1 & 12 & 802.811 & 129.583 & 37.407 \\
\hline & Product 2 & 11 & 172.632 & 41.762 & 12.591 \\
\hline \multirow[t]{2}{*}{ Plaque index DS } & Product 1 & 12 & 1.3 & .472 & .136 \\
\hline & Product 2 & 11 & .3873 & .48512 & .14627 \\
\hline \multirow{2}{*}{$\begin{array}{c}\text { Gingival index } \\
\text { DS }\end{array}$} & Product 1 & 12 & 1.0233 & .37514 & .10829 \\
\hline & Product 2 & 11 & .5782 & .50529 & .15235 \\
\hline \multirow[t]{2}{*}{ Pocket depth DS } & Product 1 & 12 & 3.0917 & .37591 & .10851 \\
\hline & Product 2 & 11 & 2.1409 & .76072 & .22936 \\
\hline
\end{tabular}

Table 1

DESCRIPTIVE STATISTICS OF THE SAMPLE

\begin{tabular}{|c|c|c|c|c|c|c|c|}
\hline & \multirow[t]{2}{*}{$\mathrm{t}$} & \multirow[t]{2}{*}{$\mathrm{df}$} & \multirow[t]{2}{*}{$\begin{array}{l}\text { Sig. (2- } \\
\text { tailed) }\end{array}$} & \multirow[t]{2}{*}{$\begin{array}{c}\text { Mean } \\
\text { Differenc } \\
\mathrm{e}\end{array}$} & \multirow{2}{*}{$\begin{array}{c}\text { Std. } \\
\text { Error } \\
\text { Differe } \\
\text { nce }\end{array}$} & \multicolumn{2}{|c|}{$\begin{array}{c}95 \% \text { Confidence } \\
\text { Interval of the } \\
\text { Difference }\end{array}$} \\
\hline & & & & & & Lower & Upper \\
\hline $\begin{array}{l}\text { IL-8 } \\
\text { DS }\end{array}$ & 15.387 & 21 & .000 & 630.178 & 40.955 & 545.008 & 715.349 \\
\hline $\begin{array}{l}\text { Plaque } \\
\text { index } \\
\text { DS }\end{array}$ & 4.596 & 21 & .000 & .917 & .199 & .502 & 1.333 \\
\hline $\begin{array}{l}\text { Gingival } \\
\text { index } \\
\text { DS }\end{array}$ & 2.413 & 21 & .025 & .445 & .184 & .061 & .828 \\
\hline $\begin{array}{l}\text { Pocket } \\
\text { depth } \\
\text { DS }\end{array}$ & 3.852 & 21 & .001 & .950 & .246 & .437 & 1.464 \\
\hline
\end{tabular}

Table 2

T-TEST FOR INDEPENDENT SAMPLESOUTPUT 


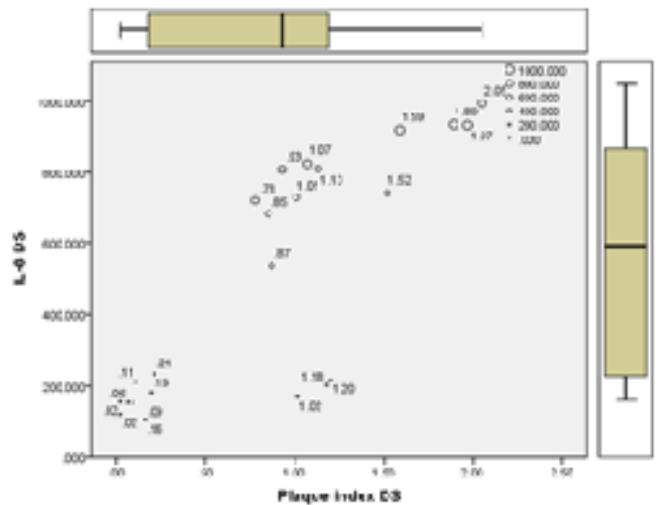

Fig. 4. Correlation between IL-8 and plaque index DS

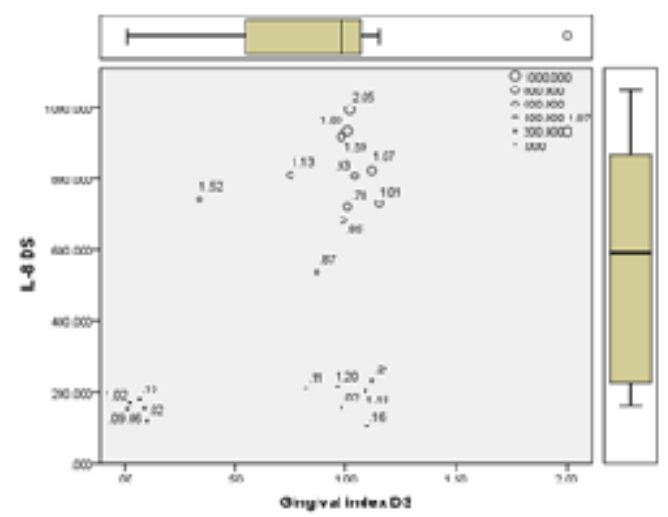

Fig. 5. Correlation between IL-8 and gingival index DS

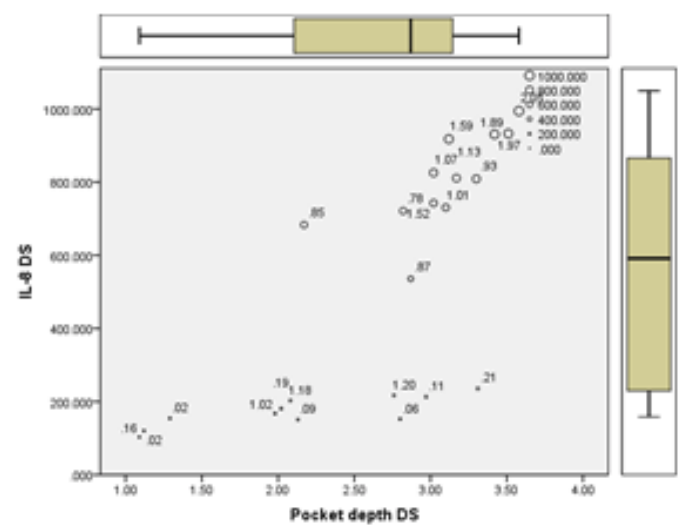

Fig. 6. Correlation between IL-8 and pocket depth DS

Normal P.P Plot of Regression Standardized Residual

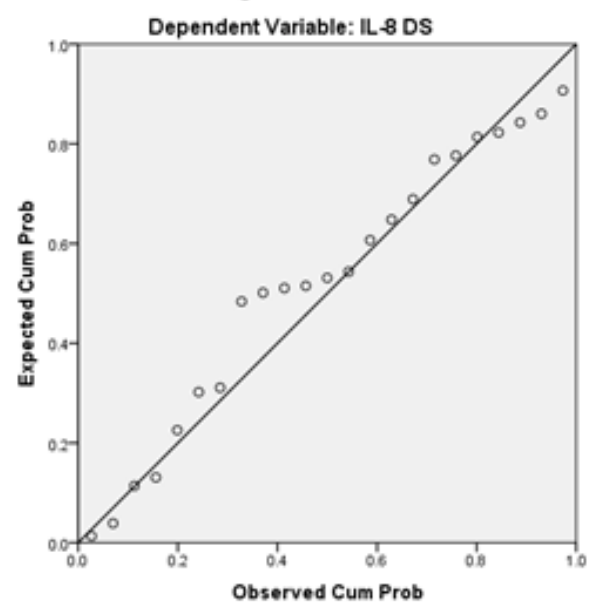

Fig. 7. Normal P-P plot of regression standardized residual very significant for IL-8 DS, plaque index DS and pocket depth DS ( $p<.001)$, and statistically significant for the gingival index DS $(p<0.05)$. The maximum effect was observed for IL-8 DS: t21 = 15.387 - the maximum value of $t$ for 21 degrees of freedom. In this case, the standard error of the mean (Std Error Mean) is more relevant for statistical purposes, since it also relates to the sample size (table 1, fig. 4-6). T-test was used for independent samples, $p=0.05$ (table 2). Figure 4 shows a very good correlation between the expected and predicted values of the generated statistical model (fig. 7).

The experiment illustrates certain aspects in polymerization reaction of methyl-methacrylate monomer (MMA) in oral cavity. Factors caused by the degree of conversion of constituent monomers, methods, and also the environment in polymerization of the applied acrylic resins caused in a complex interplay of interactions that are associated with inflammation and irritation of oral mucosa.

In our study, GCF was collected for IL-8 and TGF $\beta 1$ analysis. We tracked the expression of these cytokines in GCF based on PMMA polymerization in patients who received dental treatment with acrylic-based products. TGF $\beta 1$ was detected in a small number of cases (13.04\%). TGF $\beta 1$ is a member of cytokine family involved in mechanisms of inflammation by pro-inflammatory and anti-inflammatory effects. [8] Some study reported that GCF TGF $\beta 1$ concentrations increase inflammation induced of bacterial plaque, but the pro- or anti-inflammatory proprieties are notstill elucidated. [9] According Gurkan et al., TGF $\beta 1$ is involved in the molecular mechanisms of chronic and severe periodontitis, by excessive modulation of inflammatory markers $[10,11]$.

Interleukin 8 was detected in all studied cases, both in the disease site and in the non-disease site. Interleukin 8 is a peptide from the cytokine family, being secreted by various cell types (epithelial, conjunctive and blood cells). It is involved in the inflammatory process by inducing chemotactic activity [12]. Literature studies reported positive association of IL-8 levels and periodontal pathology status, playing an important role in the diagnosis of periodontal inflammatory process [13]. According to various studies, the levels of IL-8 in GCF were significantly higher in periodontal disease compared to healthy tissue $[14,15]$. In our study, we found that there are statistically significant differences in lesion areas, IL-8 and clinical parameters followed. At the disease site in patients treated with product 1, we identified elevated IL-8 values, (802.811 $\pm 129.583 \mathrm{pg} / \mathrm{mL}$ ) compared to product 2 (172.632 \pm $41.762 \mathrm{pg} / \mathrm{mL}$ ). These results can be explained by the release of irritant residual products during the polymerization of the material in the oral cavity. On the other hand, the structure of acrylic material in product 1 allows the adhesion of bacterial biofilm, triggers and maintains the inflammation mechanisms.

Recent studies evaluated in vitro effects of eluted acrylic products, but the results were controversial. Borzangy et al. reported that acrylic resins are not cytotoxic on epithelial cells [16]. Contrariwise, other study suggests that during polymerizing phase chemically activated resins are cytotoxic, and may affect dental pulp cells. These results should be considered in current medical practice in order to give optimal strategy of personalized therapy, especially in the case of more extensive prosthetic dental prostheses, bychoosing the right materials and the right exposure time [17]. The benefits of using termopolymerizing acrylates is that they have reduced cytotoxic effect, and produce limited inflammatory reaction if they are properly used [18]. 


\section{Conclusions}

Based on the obtained results and also based on the fact that biocompatibility refers to the ability of PMMA to performe with an appropriate host response in certain situation, we concluded that leaching the residual MMA monomer during the resin polymerization represents one of the main consequences that may influence the inflammatory reaction identified in the patient taken into this study.

It has been found that the use of block-type PMMA products does not cause inflammatory markers. These products are manufactured by complex technological processes, the polymerization of the acrylic material being completed prior to the dental therapeutical act. However, these products have high costs and involve a longer time to perform the prosthetic work, requiring fingerprinting, scanning, and specialized human resources. On the other hand, the study results are limited by the size of the statistical sample, requiring testing of the acrylic products on larger cohorts of patients.

\section{References}

1. EL-ASSAL A. Mechanical Properties of Polymethyl Methacrylate Ketoprofen Mixture in Stent and Splint Preparation. JKAU: Eng. Sci., 2004, 15(2), 33-43

2. GOIATOA MC, DOS SANTOSA DM, DE MEDEIROSA RA, MICHELINE D, ANTONIO R, FILHOA AJV, VECHIATO AJ, SINHORETIB MAC, DA SILVAA EVF, Morenoa A. Tensile Bond Strength of a Soft Liner to an Acrylic Resin after Primer Application and Thermocycling. Materials Research. 2015, 18(6), 1183-1187

3. GROVER HS, KAPOOR S, SINGH A. Effect of topical simvastatin ( 1.2 $\mathrm{mg}$ ) on gingival crevicular fluid interleukin-6, interleukin-8 and interleukin-10 levels in chronic periodontitis - A clinicobiochemical study. Jurnal of oral biological research, 2016, 6, 85-92

4. SODAGAR A, KHALIL S, KASSAEE MZ, SHAHROUDI AS, POURAKBARI $B, B A H A D O R$ A. Antimicrobial properties of poly (methyl methacrylate) acrylic resins incorporated with silicon dioxide and titanium dioxide nanoparticles on cariogenic bacteria. J Orthod Sci. 2016, 5(1), $7-13$

5. CELIKA N, ASKINB S, GULC MA, SEVENA N. The effect of restorative materials on cytokines in gingival crevicular fluid. Archives of Oral Biology, 2017, 84, 139-144
6. LOE H. The Gingival Index, the Plaque Index and the Retention Index Systems. Journal of Periodontology. 1967, 38 (6), 610-616

7. ALWAN AH. Determination of Interleukin-1 $($ IL-1 $\beta$ ) and Interleukin6(IL6) in Gingival Crevicular Fluid in Patients with Chronic Periodontitis. IOSR Journal of Dental and Medical Sciences, 2015, 14(11), 81-90

8. ALHADLAQ AM. Biomarkers of Orthodontic Tooth Movement in Gingival Crevicular Fluid. J Contemp Dent Pract. 2015,16(7), 578-587. 9. WRIGHT HJ, CHAPPLE ILC, MATTHEWS JB. Levels of TGFâ1 in gingival crevicular fluid during a 21-day experimental model of gingivitis. Oral diseases, 2003, 9(2), 88-94

10. GURKAN A, EMINGI G, CINARCIK S, BERDELI A. Gingival crevicular fluid transforming growth factor-âl in several forms of periodontal disease. Archives of Oral Biology. 2006, 51(10), 906-12

11. VIKRAM V, RAMAKRISHNAN T, ANILKUMAR K, AMBALAVANAN N. Changes in Transforming Growth Factor- $\beta 1$ in Gingival Crevicular Fluid of Patients with Chronic Periodontitis Following Periodontal Flap Surgery. Clin Diagn Res., 2015, 9(2), ZC13-ZC16.

12. GOUTOUDI P, DIZA E, ARVANITIDOU M. Effect of Periodontal Therapy on Crevicular Fluid Interleukin-6 and Interleukin-8 Levels in Chronic Periodontitis. International J ournal of Dentistry, 2012, 2012, 362905.

13. LAGDIVE SS, MARAWAR PP, BYAKOD G, LAGDIVE SB. Evaluation and comparison of interleukin-8 (IL-8) level in gingival crevicular fluid in health and severity of periodontal disease: a clinicobiochemical study. Indian J Dent Res., 2013, 24(2), 188-92

14. PAUL AM, DHAYANAND JV, PONNUDURAI S, GANA P. Role of Interleukin-8 in Periodontal Disease. IJCDS, 2012, 3(2), 32-38

15. FINOTI LS, NEPOMUCENO R, PIGOSSI SC, CORBI SC, SECOLIN R, SCAREL-CAMINAGA RM. Association between interleukin-8 levels and chronic periodontal disease: A PRISMA-compliant systematic review and meta-analysis. Liu. Y, ed. Medicine. 2017; 96(22), e6932.

16. Borzangy S, Labban N, Windsor LJ. Effects of interim acrylic resins on the expression of cytokines from epithelial cells and on collagen degradation. The J ournal of Prosthetic Dentistry, 2013, 110(4), 296-302

17. Lee JH, J un SK, Moon HJ , Lee HH. Cytotoxicity and proinflammatory cytokine expression induced by interim resin materials in primary cultured human dental pulp cells. J Prosthet Dent, 2017; 118, 524-534 18. ANTOHE, M.E., DASCALU, C., SAVIN, C., FORNA, NC, BALAN, A.., Study Regarding the Toxic Effects of Acrylic Resins, Mat. Plast., 53, no. 4, 2016, p. 767

Manuscript received: 15.11 .2017 